INTERNATIONAL FOOD POLICY

RESEARCH INSTITUTE

sustainable solutions for ending hunger and poverty

A member of the CGIAR consortium

IFPRI Discussion Paper 01261

April 2013

\title{
Data Needs for Gender Analysis in Agriculture
}

\author{
Cheryl Doss
}

Environment and Production Technology Division 


\section{INTERNATIONAL FOOD POLICY RESEARCH INSTITUTE}

The International Food Policy Research Institute (IFPRI) was established in 1975 to identify and analyze national and international strategies and policies for meeting the food needs of the developing world on a sustainable basis, with particular emphasis on low-income countries and on the poorer groups in those countries. IFPRI is a member of the CGIAR Consortium.

\section{PARTNERS AND CONTRIBUTORS}

IFPRI gratefully acknowledges the generous unrestricted funding from Australia, Canada, China, Denmark, Finland, France, Germany, India, Ireland, Italy, Japan, the Netherlands, Norway, the Philippines, South Africa, Sweden, Switzerland, the United Kingdom, the United States, and the World Bank.

\section{AUTHOR}

Cheryl Doss, Yale University

Senior Lecturer, Global Affairs and Economics

cheryl.doss@yale.edu

Notices

IFPRI Discussion Papers contain preliminary material and research results. They have been peer reviewed, but have not been subject to a formal external review via IFPRI's Publications Review Committee. They are circulated in order to stimulate discussion and critical comment; any opinions expressed are those of the author(s) and do not necessarily reflect the policies or opinions of IFPRI

Copyright 2013 International Food Policy Research Institute. All rights reserved. Sections of this material may be reproduced for personal and not-for-profit use without the express written permission of but with acknowledgment to IFPRI. To reproduce the material contained herein for profit or commercial use requires express written permission. To obtain permission, contact the Communications Division at ifpri-copyright@cgiar.org. 


\section{Contents}

Acknowledgments $\quad$ iv

Abstract $\quad \mathrm{V}$

1. Introduction 1

2. Structure and Approach to Data Collection for Gender Analysis 3

3. Questions to Include 6

4. Data for Intrahousehold Analyses $\quad 10$

5. Conclusion 11

References 12 


\section{ACKNOWLEDGMENTS}

This paper was written as part of an edited volume of background papers for the State of Food and Agriculture 2010-2011: Women and Agriculture: Closing the gender gap for development. IFPRI acknowledges funding from the Food and Agriculture Organization and the Bill and Melinda Gates Foundation for work that is included in that volume. 


\begin{abstract}
To support gender analysis in agriculture, household surveys should be better designed to capture genderspecific control and ownership of agricultural resources such as male-owned, female-owned, and jointly owned assets. This paper offers guidelines on how to improve data collection efforts to ensure that women farmers are interviewed and that their voices are heard. Researchers need to clarify who should be interviewed, how to structure the interview, and how to identify which people are involved in various activities, as owners, managers, workers, and decisionmakers. It is important not simply to assume that one particular person does these activities based on social norms, but instead to ask the questions to allow for a range of answers that can demonstrate how the gender patterns in agriculture are changing. To assist in these efforts, the paper provides an overview of relevant questions to include, emphasizing that whenever questions are asked about ownership and access to resources, answers should be associated with individuals. Finally, collecting data on the institutions that are related to agricultural production and marketing allows analysis of the gender-based constraints and opportunities that they present.
\end{abstract}

Keywords: agriculture, gender, survey design, household decisionmaking 



\section{INTRODUCTION}

Understanding the role that gender plays in agricultural production is critical for designing agricultural policies to increase productivity and enhance economic growth and to reduce poverty. Although there is increasing awareness of the importance of including women in agricultural policies, either through explicit programs for women or through mainstreaming approaches, key data gaps still exist that inhibit the development of appropriate policies and monitoring their progress.

Gender analysis examines how the social roles of men and women are determined and how those roles affect the outcomes being studied. Although the term gender analysis is often used to refer to studies that look at women, it is not possible to study women's behavior without considering the broader contexts facing both women and men. Gender analysis examines how the roles, rights, and responsibilities of men and women interact and how that affects outcomes. In agriculture, gender analysis provides insights into how socially constructed roles and responsibilities shape the myriad decisions around agricultural production and processing.

We must understand the constraints and opportunities people face to develop appropriate agricultural policies. Such constraints and opportunities are often influenced and shaped by gender, and thus incorporating gender into the analyses is critical. For example, labor markets differ for men and women (see Dey de Pryck and Termine forthcoming). The decision regarding the type of work to seek, whether in the formal or informal sector, depends on social norms about household responsibilities and the availability of appropriate work and the potential earnings. These all vary by gender. Similarly, both the supply of and the demand for credit varies for men and women. Thus, to understand credit markets, one must understand how gender influences the decision to seek credit, the sources available, and the probability of obtaining credit.

Two broad sets of questions about agriculture are frequently asked. The first is how to increase agricultural productivity. What are the constraints to improved productivity and what policies are needed to ease them? These may include constraints to the adoption of new technologies or inefficiencies in markets. These questions lead into macroeconomic ones about how to use agriculture to promote economic growth. Gender is often left out of these analyses or included only in a very cursory way, such as including a measure of the sex of the household head in the analysis.

A second set of questions is specifically about women and agriculture, asking whether women are being left behind or made worse off with the introduction of new technologies and new marketing opportunities. These analyses may look at the gender gaps, demonstrating the disadvantages that women face as farmers. The State of Food and Agriculture 2010-2011, Women in Agriculture: Closing the Gender Gap for Development has identified many such gaps, but the analysis often points to the deficiencies in the data available (FAO 2011). The statistical appendix for The State of Food and Agriculture 2010-2011 is impressive for its coverage of countries, but also for its heroic attempt to identify the many gaps. There are many countries and variables for which the information is not available. The data that is available clearly demonstrate the existence of gender differences with significant consequences. But in many contexts, the data are not available and local policymakers need national-level data on the gender gaps in their country.

Work on impact assessment is related to both sets of questions. Some of it examines how changes in agricultural policy or agricultural programs affect poverty. There is growing awareness that these impacts may be different for men and for women. Yet the data are not always available or collected to support this analysis. Other work specifically considers the impact on women, often suggesting that the technologies may actually harm women or some groups of women.

To analyze these various questions about agriculture, data are needed at two different levels. The first is that much more of the microlevel data needs to be sex-disaggregated, which will require that the data be collected at the level of the individual, rather than just at the household or farm level, or that data are collected both on the agricultural holdings and on the holder. Collecting additional data at the individual level will facilitate not only gender analyses but also a broader range of analyses across 
individuals based on age, status within the household, and other individual characteristics. Thus, while the benefits of collecting disaggregated data are critical for gender analysis, they will serve a much broader purpose as well. Second, data are needed for researchers to analyze how institutions and structures, such as markets for inputs and outputs, credit markets, and labor markets, are experienced differently by men and women and how this has an impact on the well-being of individuals and communities and the processes of agricultural development and economic growth. This may require information collected at the regional, community, household, and individual levels on control over resources, decisionmaking, contributions of labor, and so on.

Some of the necessary changes in data collection are quite simple and would require little or no additional resources. These changes should be implemented in all agricultural surveys to considerably improve the data that are available. In other instances, more detailed questions would need to be added and trade-offs will be faced about the breadth and depth of the questionnaires.

Explicitly incorporating gender analysis into discussions of agricultural productivity should also expand the definitions of agricultural production to include a greater level of processing and preparation, much of which is done by women. Incorporating the full range of agricultural production, from farm to table, would provide better insights into some of the constraints both male and female farmers face.

The remainder of this paper focuses on the quantitative data needed for gender analysis that can be collected in surveys and censuses. A discussion of combined qualitative and quantitative approaches is provided in Behrman, Meinzen-Dick, and Quisumbing (forthcoming). This paper begins with a discussion of the types of agricultural surveys and asks who should be interviewed. It then moves to a discussion of specific types of questions that should be asked. 


\section{STRUCTURE AND APPROACH TO DATA COLLECTION FOR GENDER ANALYSIS}

In considering the data needed, it is important to consider who should be interviewed and how to structure the interview. These will depend on the research or policy questions that need to be answered, and the appropriate unit of analysis. Are we interested in the farmer, the household, the plot of land, a particular crop, the farm enterprise? Different units of analysis will lend themselves to different types of surveys.

Broadly, the types of surveys used for analyses of agriculture include farmer surveys, household surveys, labor market surveys, and agricultural censuses. Each provides different information and helps to answer different questions. Because they use different sampling frames, the data on similar issues may differ across these types of surveys. Each type of survey has its strengths and weaknesses and should be considered in the context of the broader research questions.

Farmer surveys typically interview individual farmers. ${ }^{1}$ They ask detailed questions about the production process and sales and marketing of output. Frequently, farmer surveys focus on a particular crop or set of crops. A farmer survey may interview maize farmers or rice farmers to learn about their production challenges and constraints. The strength of farmer surveys is the ability to collect very detailed data about such crops. A disadvantage is that the crops may not be considered in the context of the broader choices that the farmer and his or her household are making. By focusing a survey on a particular crop, especially a cash crop or major staple crop, many of the other agricultural activities may be ignored. The other crops and activities may be small but important sources of income for individuals within the household or contribute to household food security. Involvement with these crops may limit the amount of labor available to the major crops. This focus on the major crops may provide good approximations of the total output from a holding but miss components, especially those done and controlled by women.

Since agricultural activities, especially among smallholder farmers, are embedded in a range of household activities, household surveys are often used to analyze agricultural decisions. Household surveys usually treat the household as the production and consumption unit. ${ }^{2}$ They facilitate analysis that can encompass the range of decisions that households are making, such as which crops to grow, whether to engage in off-farm labor, whether to send their children to school, and how much of the farm output to sell in order to purchase other items. Thus, they provide a better means for understanding livelihood decisions, but may have less detailed information on specific crop production practices. When done well, household surveys can provide the data needed for researchers to analyze the trade-offs that people are making across different activities, both agricultural and nonagricultural.

The line between farmer surveys and household surveys is somewhat blurry, but it is useful to conceptualize them differently. A farmer survey focuses on a particular crop or crops and collects detailed data on the production and marketing. Household surveys seek to understand the range of household activities and the interactions among them.

An agricultural census usually involves complete enumeration of all agricultural holdings in a country. This is different from surveys that sample a relatively small number of farmers or households. In a census, the agricultural holder for each holding is interviewed and a limited amount of data is obtained about the holding. The Food and Agriculture Organization of the United Nations recommends that a country conduct an agricultural census once every 10 years in order to provide information on all holdings (FAO 2005a). The amount of information on each holding is relatively small compared with that gathered by farmer or household surveys, but together they provide a picture of the entire agricultural sector.

\footnotetext{
${ }^{1}$ Many small-sample farmer surveys are collected through the Consultative Group on International Agricultural Research centers. The analysis by Doss and Morris (2001), discussed later in this paper, is based on a survey where the unit of analysis was maize farmers in Ghana.

${ }^{2}$ The World Bank Living Standards Measurement surveys are examples of multipurpose household surveys that usually include a substantial agricultural module or modules.
} 
Finally, labor force surveys may be relevant for agricultural analyses. They are household-based surveys that collect data on the economically active population, employment, and unemployment. Because they ask about employment in the agricultural sector, they provide aggregate statistics on the agricultural workforce. Data are typically collected on all household members. These data are used to report the share of the population working in agriculture and to examine trends in the agriculture workforce. ${ }^{3}$

Each of these different types of survey has advantages and disadvantages when considering how it can be used for gender analysis. The structure of the survey influences who is interviewed.

A key challenge for all agricultural surveys is to ensure that women farmers are represented and counted. This challenge is at three levels. First, for surveys that are interviewing "farmers," one must not assume simply that the farmer is a man. The farmer is usually defined as the person who makes the major agricultural decisions or the person who knows the most about the agricultural production. It is important that questions be asked to identify the appropriate respondent. In addition, for agricultural censuses, the FAO now recommends that the data collection allow for joint holders as well as individual holders of parcels, where the holder is defined as the person or persons making the major decisions.

Second, even when a man makes the major agricultural decisions, a woman may make the decisions for specific crops or activities. The FAO guidelines suggest that agricultural censuses ask about subholdings and subholders, specifically because women often manage small plots within agricultural holdings (FAO 2005a). ${ }^{4}$ In many places, if men are culturally defined as the decisionmakers, asking about who makes the agricultural decisions overall will usually result in a male being identified as the farmer. Yet asking about the decisions over other specific activities, such as specific crops or animals, may result in women being identified.

Finally, even when women are not interviewed as the major decisionmakers for holdings or subholdings, they may make a substantial contribution to agricultural production. It is important to count their contributions and to identify the opportunities and constraints that they face.

The latter two concerns suggest that interviewing more than one person in the household may be necessary if the survey is interested in obtaining data on the full range of agricultural production done in the household. One recent study suggests that it is important to interview both the husband and wife to obtain complete information on household income from farm households in Malawi (Fisher, Reimer, and Carr 2010). Husbands did not report full information on their wives' incomes. For a smallholder farm, it may not be the case that one person owns the land and makes all of the agricultural decisions, from what to plant to how and where to sell the output. For example, the owner of the land may not be the person who makes the key decisions about what crops to plant. ${ }^{5}$ This issue of identifying domains of decisionmaking is particularly relevant when a husband migrates, leaving his wife responsible for the day-to-day operations of the farm. Depending on whether he is on the farm at the time of the survey, either one of them may be interviewed. ${ }^{6}$ Thus, it is useful to ask about the various decisionmaking domains of the respondent identified as the farmer.

Many studies use household-level data and consider gender just at the level of the household head. Thus, comparisons are made of the responses across male-headed and female-headed households. However, since women frequently live in male-headed households, but adult men rarely live in households that are defined as female-headed, this approach conflates measures of household structure

\footnotetext{
${ }^{3}$ The labor force results may be affected by how the questions are asked and to whom they are addressed (Bardasi et al. 2011).

${ }^{4}$ The publication Agricultural Censuses and Gender: Lessons Learned in Africa (FAO 2005b) raised many issues about collecting agricultural census data that can be used for gender analysis. Some of those concerns have been incorporated into the FAO recommendations.

${ }^{5}$ See Doss (2001) for a discussion of how the categorization into men's and women's crops varies depending on whether the definitions are based on the sex of the head, landholder, decisionmaker, or person who keeps the revenue.

${ }^{6}$ As cell phone availability increases rapidly in rural areas, it is not at all clear how this will have an impact on decisionmaking on farms, since a person would not have to be physically present in order to be involved in the process.
} 
and composition with the gender of the head. And considering only the sex of the head of household renders women living in male-headed households invisible.

A number of empirical studies demonstrate the range of problems with simply using the sex of the household head in gender analysis. Doss and Morris (2001) find that in Ghana, after taking into consideration the age and education of the farmer, access to land and labor, contact with extension, and market access, no difference exists between male and female farmers as to the probability of planting improved varieties of maize or using fertilizer. ${ }^{7}$ Living in a female-headed household, however, does reduce the probability of adopting those technologies. If they had considered only the heads of household, they would have missed the female farmers living in male-headed households who are adopting the improved technologies. Similarly, Peterman et al. (2011) find that using measures at the plot level, rather than indicators of the sex of the household head, results in different conclusions about the extent of gender differences in agricultural productivity. Finally, Deere, Alvarado, and Twyman (2010) demonstrate how using the sex of the household head underestimates women's ownership of assets, including land and housing.

A broader critique of the notion of household headship and how it is defined is articulated by Budlender (2003). Household heads may be defined by age, sex, custom, or economic contributions, among other factors, and may differ widely across contexts and, if not clearly defined in surveys, across enumerators. Many member countries in the Organization for Economic Cooperation and Development are moving away from the notion of a household "head" within their data collection exercises, and Budlender argues that particularly in the context of households that may be extended family units, polygamous, or multigenerational, or a combination thereof, defining a single household head is not a useful means of understanding the relationships among the household members.

In addition, surveys use a multiplicity of definitions of the household. Typically, the household is defined as people who sleep under the same roof, eat out of the same pot, and share in production and consumption activities. But these different components may result in different people being included within the household. Beaman and Dillon (2012) report on the results of an experiment in survey design where different definitions of the household were used. They find that there are statistically significant differences across reported household size and composition, depending on the definitions that are used. Their results suggest that it is important to consider the appropriate definition of the household for the research questions being analyzed.

Thus, it is not appropriate to simply automatically interview the person considered to be the male head of household. If focusing on a particular crop or activity, it is important to interview the person who makes decisions or is most knowledgeable; this may be a man or a woman. If the goal is to understand rural livelihoods and to identify and evaluate potential strategies for poverty reduction, it is critical to interview multiple people within the household and ask about multiple activities. And finally, to understand intrahousehold dynamics, detailed data are needed on the key actors (usually the principal couple, but intergenerational dynamics within the household may be the focus), and those data need to include information on the various factors that may affect actors' bargaining power as well as on their roles and responsibilities in agricultural production.

\footnotetext{
${ }^{7}$ Women are less likely overall to adopt the improved technologies because of their lower levels of education, access to land and labor, and contact with extension; see the review in Peterman et al., forthcoming.
} 


\section{QUESTIONS TO INCLUDE}

For gender analysis, it is important to attribute the roles and responsibilities of agricultural production to the individual. Thus, whenever the survey asks questions about ownership and access to resources, answers should be associated with individuals. In addition, to the extent possible, it is useful to attribute the outputs to individuals, acknowledging that there are conceptual issues with this enterprise (see Doss forthcoming). Finally, collecting data on the institutions that are related to agricultural production and marketing allows analysis of the gender-based constraints and opportunities that they present.

The following discussion indicates key areas in which individuals need to be identified so that gender can be included in the analysis. Basic demographic data are needed on all of the people involved in the agricultural production process. Although that certainly includes the holder and subholders, it also includes those who provide paid and unpaid labor on the holding and those who are involved in the decisionmaking. The minimum demographic data needed are sex, age, education level, marital status, and relationship to household head or respondent for each of these people. All of these characteristics may affect the roles that the individual plays in agricultural production. Marital status may affect one's status within the community and one's access to both land and social networks. Widows and women who are divorced, in particular, may have less access to a variety of resources, especially land. Marital status may also frame how decisions are made within the household; even when women are defined as the farmer, their role as decisionmakers may vary, depending on whether they are married.

In this section, the assumption is that the gender analysis is going to be carried out within the broader context of a data collection and analysis exercise that is already collecting much of the standard agricultural information. Thus, this does not go into detail on all of the information that should be collected, but simply identifies areas that need specific attention to facilitate gender analysis in agriculture.

\section{Productive Resources}

One issue is to identify the owners of and the people who have access to key resources and inputs. The concept of an individual owner who has the entire bundle of rights over the asset may not hold in many rural areas. For example, for land, an individual may have the right to farm the land but may or may not have the right to sell or mortgage it. Or he or she may have the right to grow annual crops but may not have the right to plant trees. To understand the agricultural production decisions, especially those involving long-term investment, it is important to understand people's rights and tenure security over the land. The same may be true of livestock; one individual may have the right to sell the animal whereas another member of the household may have the milking rights. ${ }^{8}$

Agricultural surveys usually ask questions about land tenure and various characteristics of the land, but they often overlook two key elements of the land tenure system that are critical for gender analysis. Many surveys ask about the tenure system under which the land is accessed and whether the respondent (or someone in the household) owns the land. If the land is owned, then the follow-up question is whether there is a title or other document for the land. The additional questions that are needed are which household member or members own the land and whose names are on the documents. Because multiple household members may be owners, knowing whether the farmer owns it individually or jointly with a spouse or other family member is important. The rights and decisionmaking may vary depending on who owns the land. In addition, asking which names are on the ownership documents allows for gender analysis because it identifies the gender of the legal owner. It may also provide insights into intergenerational transfers of land, since it is not uncommon for an adult child to farm land that is still legally in a parent's name.

\footnotetext{
${ }^{8}$ See Meinzen-Dick et al. (1997) for a discussion of property rights and gender in the context of natural resources.
} 
Data on the mode of acquisition of land and other assets may also be important (see LastarriaCornhiel et al. forthcoming). Purchased land may have a more complete set of rights, including the rights to sell and mortgage, than land that was inherited or allocated under customary tenure. There may be differences among men and women regarding how assets are acquired. (See Quisumbing et al. 2001 for Ghana and Doss et al. 2011 for Uganda.)

Especially in Africa and other places where much land is not formally titled, the issue of access to land and tenure security may be as relevant as the formal ownership of land. The security of tenure and rights of access may influence investment and production decisions. Since women who claim ownership may have fewer rights than men who claim ownership, it is useful to have data on both the reported ownership and the specific rights over the asset. In a recent study in rural Uganda, although many women were reported as jointly owning land with their husband, very few of those households had some form of ownership documents (typically not titles, but sales receipts), very few of the women's names were on the documents, and women claimed fewer rights over the land than men (Bomuhangi, Doss, and MeinzenDick 2011).

Similarly, surveys should include individual-level ownership questions on livestock. A frequent generalization is that men own and manage large stock, such as cattle, while women own and manage small stock, such as sheep and goats, and poultry. Yet it is important to interrogate these assumptions. Even among pastoralists in northern Kenya and southern Ethiopia, groups who are usually considered to be very patriarchal, McPeak, Little, and Doss (2011) found that women did report owning large animals, including both cattle and camels. Women did own fewer animals than men overall, but assuming that women owned no large animals could lead to wrong policy prescriptions.

Finally, ownership of other key productive resources, such as agricultural equipment, should be included. Women farmers who live in households that have some agricultural equipment but who do not own the equipment themselves may have last claims to use it, making timely planting or harvesting difficult.

In addition to data on ownership of the productive assets, knowing who manages or has control over them is also useful. For livestock, in particular, the owner may not be the one actually managing the animals, so information on who makes the daily decisions is important. The gender patterns in livestock ownership and management are changing - women and girls may become more involved with the livestock as men migrate or have wage jobs (also, see Kristjanson et al.forthcoming).

\section{Labor}

Labor is the other key input into agricultural production. Great strides have been made in collecting individual-level data on formal-sector employment and wages and benefits. The data that are now often routinely available allow for the gendered analysis of patterns of formal employment and wages. Data on formal-sector work are easier to collect than data on nonformal-sector work or work within the household, including agricultural production.

Deere (2005) identifies four reasons women's labor may be undercounted in population and agricultural censuses, based on her work in Latin America. First, she argues that rural women are likely to report their home as their principal occupation, even when they are actively engaged in agricultural production. Second, the censuses ask about income-generating activities, thus undercounting subsistence production. Third, the definition of agriculture is often narrow, focusing on fieldwork, leaving out a range of predominantly women's activities, including raising livestock, tending kitchen gardens, and agricultural processing. Finally, Deere claims that the practice of censuses of defining economic activity as involving a minimum number of hours of work in the week prior to the survey for certain categories, such as for unpaid family workers but not for the primary farmer, results in the undercounting of women due to the seasonality of agricultural work. 
At a minimum, if agricultural surveys ask about the various tasks being done, they should disaggregate by age and sex. Men's and women's labor has often not been interchangeable in agricultural production, but the patterns of activity are changing and data are needed to document this. Women are involved in many traditionally male tasks; and men are increasingly involved in activities that have a higher return, regardless of whether the crops were traditionally women's crops.

In addition to details on employment and agricultural work, collecting information on time use sheds light on how people are allocating their time across productive and reproductive activities and leisure. ${ }^{9}$ This provides a means to analyze the trade-offs across these various sets of activities.

A number of small-sample time-use studies were conducted for rural households in various places in Africa during the $1980 \mathrm{~s} .{ }^{10}$ These studies not only emphasized women's important contributions to agricultural production, but also quantitatively demonstrated women's roles in agricultural processing and food preparation. Fewer time-use studies have focused on the rural sectors in recent years. Yet as the agricultural sector transforms, time-use data are critical to understanding how people allocate their time within and outside the sector. Recent work has emphasized the issue of "time poverty" among the poor and note that it is especially severe for poor women (Blackden and Wodon 2006).

\section{Yield and Output}

To the extent possible, it is useful to attribute the output of agricultural production to individuals. Rather than asking about total output at the household or holding level, collecting such data at the plot or subholding level provides one way to attribute output to the individual or joint holders of the land. Similarly, knowing about which people are managing and controlling the outputs from livestock, including milk, eggs, and meat, allows the attribution of such outputs to men and women within households.

Full income, including both cash income and the value of the goods and services produced and consumed within the household, is a useful measure of well-being. Income measures are typically used to categorize households - and sometimes individuals - as poor or nonpoor. Income from agricultural production is often not collected in such a way to allow the attribution of any of the income to individuals. But by attributing the output to individuals, based on either management or labor inputs, individual-level income can be estimated.

There is now a substantial literature that suggests that expenditure patterns and other household outcomes vary, depending on whether income is earned or received by men or women. ${ }^{11}$ The differences in outcomes may be due to relative changes in the prices of purchased and home-produced goods when individual household members are employed or because individual income confers bargaining power within the household. This suggests that it is important to have data on both household income and income at the individual level.

In addition, if we are interested in the dynamics within households, the various sources of income, or women's status and income-generating opportunities, then collecting information on all sources of income by individual may be important. Without attention to this detail, we may easily ignore many of the small sources of income that women have. These smaller sums of money may have important implications for the well-being of the women themselves, since they often control this income. And their control of this money may determine how it is spent. Thus, policies that affect these sources of income might have a relatively large impact on household well-being or expenditures on particular types of goods, but these relationships could not be identified if data on only the major sources of income were collected or if the data were only collected at the household level.

\footnotetext{
${ }^{9}$ For a discussion of time-use surveys in developing countries, see Hiway (2009).

${ }^{10}$ These are discussed in more detail in Doss (forthcoming).

${ }^{11}$ See, for example, Hoddinott and Haddad (1995) on agricultural income, Schultz (1990) on unearned income, and Doss (2001) and Duflo and Udry (2004) on shocks to income and the effects on household outcomes, including expenditures and labor force participation.
} 
To understand the different constraints men and women face, it is useful to have data on their participation in a range of agricultural institutions. Women typically have had less access to extension services and agricultural credit (see Ragasa forthcoming). Extension is moving increasingly from the government sector to the private sector, and it is important to know how this change is affecting women. And although microcredit has often targeted women, larger-scale agricultural credit is still often out of their reach. Data on which individuals access these resources are needed to understand who is being left out and to track programs to provide such resources. This would include whether they have contact with extension workers, participate in farmer's groups, obtain credit, and sell produce in the market. Simply knowing who participates is not sufficient to prescribe how to ease the constraints, but it provides useful baseline information. This information may be collected at the individual or institutional level, by examining who uses the services provided. 


\section{DATA FOR INTRAHOUSEHOLD ANALYSES}

Analysis at the household level is often insufficient to understand either the welfare effects of policies or the responses to policies implemented at community or national levels. Household-level responses to policies often depend on who is living within the household and who within the household is making the decisions. An extensive literature suggests that not all members of the household share equally in the benefits of the household (see, for example, Haddad and Kanbur 1990). Evidence suggests that women frequently have less access to household resources than do men. Numerous microlevel studies have demonstrated that households do not respond as expected to incentives, in part because there is not a single household decisionmaker who is optimizing based on incentives (see, for example, Udry 1996). Instead, both cooperation and conflict occur among household members, and those shape the responses that are observed as being household responses (Sen 1990).

Many of the changes to data collection proposed in this paper will provide greater opportunities for intrahousehold analyses. Intrahousehold analyses and gender analyses often overlap, but they are not synonymous. Frequently, intrahousehold analyses assume that the key differences are based on gender and thus test the hypothesis, for example, that giving income to women or giving women increased bargaining power within the household will have an impact on the outcome of household decisions. This approach implicitly assumes that gender defines the key differences in preferences, whereas other considerations, such as age and relationship to the head of household, also come into play. Thus, demonstrating that income in the hands of women is more likely to be spent on children implicitly assumes women, as a group, have a greater preference for spending money on children. It does not allow us to explicitly test the hypothesis that the individual who receives the money can choose how to spend it. More data at the individual level would allow some of these assumptions to be tested, benefiting both intrahousehold analyses and gender analyses. Yet gender analysis is broader than intrahousehold analysis. It examines how gender shapes behavior not only within the household, but also at the community, institutional, and national levels.

Although this paper argues that individual-level data and analysis are critical, household-level analysis of poverty and development issues will continue to be important as well. Many decisions are made within the contexts and constraints of households. Analyses typically take the household structure as given, but household structure can often be affected by the very policies that are being implemented and analyzed. Thus, understanding how households are formed is important. Although panel data would be useful for a full analysis of household formation and dissolution, with a few additional questions in multipurpose surveys, we can improve the data available to analyze household structure and to begin to examine the impact of policies on household structure.

One final set of questions, addressing how decisions are made within the household, includes questions about both production, including agricultural production, and consumption. An extensive literature now concludes that it is inappropriate to assume that the household acts as a unitary decisionmaker (Alderman et al. 1995). Instead, we should consider the characteristics of the individuals within the household and the dynamics among them to understand how decisions are made. Thus, the structure and composition of the household and the age and education levels of household members will all influence the outcomes of decisions. In addition, the bargaining power of individual household members may also influence the outcomes. Typically, researchers have analyzed how the bargaining power of the principle couple within the household, often thought of as the head and spouse, affects outcomes. 


\section{CONCLUSION}

To support gender analyses in agriculture, data collection efforts need to do two things. First, they need to ensure that women farmers are interviewed and that their voices are counted. Second, the information should identify which people are involved in various activities, as owners, managers, workers, and decisionmakers. It is important not simply to assume that one particular individual does these activities based on social norms, but instead to ask the questions to allow for a range of answers that can demonstrate how the gender patterns in agriculture are changing.

Agricultural researchers and policymakers continue to struggle with numerous other questions. For instance, there are the broader questions about how to improve agricultural productivity and how increased agricultural productivity is related to economic growth. Often these questions, especially those at the macro level about agricultural productivity and economic growth, do not include any gender analysis. Yet to answer such questions effectively - and obtain the correct answers - it is important to incorporate gender into the analysis. And thus, this requires appropriate sex-disaggregated data. 


\section{REFERENCES}

Alderman, H., P. A. Chiappori, L. Haddad, J. Hoddinott, and R. Kanbur. 1995. "Unitary versus Collective Models of the Household: Is It Time to Shift the Burden of Proof?" World Bank Research Observer 10 (1): 1-19.

Bardasi, E., K. Beegle, A. Dillon, and P. Serneels. 2011. "Do Labor Statistics Depend on How and to Whom the Questions Are Asked? Results from a Survey Experiment in Tanzania." World Bank Economic Review 25 (3): 418-447.

Beaman, L., and A. Dillon. 2012. "Do Household Definitions Matter in Survey Design? Results from a Randomized Survey Experiment in Mali." Journal of Development Economics 98 (1): 124-135.

Behrman, J. A., R. Meinzen-Dick, and A. Quisumbing. Forthcoming. "Understanding Gender and Culture in Agriculture: The Role of Qualitative and Quantitative Approaches.” Ch. 2 in Gender in Agriculture and Food Security: Closing the Knowledge Gap, edited by A. Quisumbing, R. Meinzen-Dick, T. Raney, A. Croppenstedt, J. A. Behrman, and A. Peterman. Springer and FAO.

Blackden, C. M., and Q. Wodon, editors. 2006. Gender, Time Use, and Poverty in Sub-Saharan Africa. World Bank Working Paper 73. Washington, DC: World Bank.

Bomuhangi, A., C. Doss, and R. Meinzen-Dick. 2011. Who Owns the Land? Perspectives from Rural Ugandans and Implications for Land Acquisitions. IFPRI Discussion Paper 01136. Washington, DC: International Food Policy Research Institute.

Budlender, D. 2003. “The Debate about Household Headship.” Social Dynamics 29 (2): 48-72.

Deere, C. D. 2005. The Feminization of Agriculture? Economic Restructuring in Rural Latin America. Occasional Paper 1. Geneva: UN Research Institute for Social Development.

Deere, C. D., G. E. Alvarado, and J. Twyman. 2010. Poverty, Headship, and Gender Inequality in Asset Ownership in Latin America. Working Paper 296. East Lansing, MI, US: Center for Gender in Global Context, Michigan State University.

Dey de Pryck, J., and P. Termine. Forthcoming. "Gender Inequalities in Rural Labor Markets." Ch. 14 in Gender in Agriculture and Food Security: Closing the Knowledge Gap, edited by A. Quisumbing, R. Meinzen-Dick, T. Raney, A. Croppenstedt, J. A. Behrman, and A. Peterman. Springer and FAO.

Doss, C. 2001. "Is Risk Fully Pooled within the Household? Evidence from Ghana." Economic Development and Cultural Change 50 (1): 101-130.

. Forthcoming. "If Women Hold up Half the Sky, How Much of the World's Food Do They Produce?" Ch. 4 in Gender in Agriculture and Food Security: Closing the Knowledge Gap, edited by A. Quisumbing, R. Meinzen-Dick, T. Raney, A. Croppenstedt, J. A. Behrman, and A. Peterman. Springer and FAO.

Doss, C., and M. Morris. 2001. "How Does Gender Affect the Adoption of Agricultural Innovations? The Case of Improved Maize Technology in Ghana." Agricultural Economics 25 (1): 27-39.

Doss, C., M. Truong, G. Nabanoga, and J. Namaalwa. 2011. Women, Marriage, and Asset Inheritance in Uganda. Working Paper 184. Manchester, UK: Chronic Poverty Research Center.

Duflo, E., and C. Udry. 2004. Intrahousehold Resource Allocation in Côte d'Ivoire: Social Norms, Separate Accounts, and Consumption Choices. Working Paper 10498. Washington, DC: National Bureau of Economic Research.

FAO (Food and Agriculture Organization of the United Nations). 2005a. A System of Integrated Agricultural Censuses and Surveys, vol. 1. World Programme for the Census of Agriculture 2010. Rome. . 2005b. Agricultural Censuses and Gender: Lessons Learned in Africa. Rome.

2011. The State of Food and Agriculture 2010-2011. Women in Agriculture: Closing the Gender Gap for Development. Rome.

Fisher, M., J. Reimer, and E. Carr. 2010. "Who Should Be Interviewed in Surveys of Household Income?” World Development 38 (7): 966-973. 
Haddad, L., and R. Kanbur. 1990. "How Serious Is the Neglect of Intrahousehold Inequality?" Economic Journal 100 (402): 866-881.

Hiway, I. 2009. "Time Use Surveys in Developing Countries: An Assessment.” In Unpaid Work and the Economy: Gender, Time Use, and Poverty in Developing Countries, edited by R. Antonopoulos and I. Hiway, 252324. Basingstoke, Hampshire, UK: Palgrave Macmillan.

Hoddinott, J., and L. Haddad. 1995. "Does Female Income Share Influence Household Expenditure Patterns? Evidence from Côte d'Ivoire." Oxford Bulletin of Economics and Statistics 57 (1): 77-96.

Kristjanson, P., A. Waters-Bayer, N. Johnson, A. Tipilda, J. Njuki, I. Baltenweck, D. Grace, and S. MacMillan. Forthcoming. "Livestock and Women's Livelihoods: A Review of the Recent Evidence." Ch. 9 in Gender in Agriculture and Food Security: Closing the Knowledge Gap, edited by A. Quisumbing, R. MeinzenDick, T. Raney, A. Croppenstedt, J. A. Behrman, and A. Peterman. Springer and FAO.

Lastarria-Cornhiel, S., J. A. Behrman, R. Meinzen-Dick, and A. R. Quisumbing. Forthcoming. "Gender Equity and Land: Toward Secure and Effective Access for Rural Women." Ch. 6 in Gender in Agriculture and Food Security: Closing the Knowledge Gap, edited by A. Quisumbing, R. Meinzen-Dick, T. Raney, A. Croppenstedt, J. A. Behrman, and A. Peterman. Springer and FAO.

McPeak, J., P. Little, and C. Doss. 2011. Risk and Social Change in an African Rural Economy: Livelihoods in Pastoralist Communities. New York: Routledge.

Meinzen-Dick, R., L. R. Brown, H. Sims Feldstein, and A. R. Quisumbing. 1997. “Gender, Property Rights, and Natural Resources." World Development 25 (8): 1303-1316.

Peterman, A., A. R. Quisumbing, J. Behrman, and E. Nkonya. 2011. "Understanding the Complexities Surrounding Gender Differences in Agricultural Productivity in Nigeria and Uganda." Journal of Development Studies 47 (10): 1482-1509.

Peterman, A., J. Behrman, and A. R. Quisumbing. Forthcoming. A Review of Empirical Evidence on Gender Differences in Non-Land Agricultural Inputs, Technology, and Services in Developing Countries, in Gender in Agriculture and Food Security: Closing the Knowledge Gap, edited by A. Quisumbing, R. Meinzen-Dick, T. Raney, A. Croppenstedt, J. A. Behrman, and A. Peterman. Springer and FAO.

Quisumbing, A. R., E. Payongayong, J. B. Aidoo, and K. Otsuka. 2001. "Women's Land Rights in the Transition to Individualized Ownership: Implications for the Management of Tree Resources in Western Ghana." Economic Development and Cultural Change 50 (1): 157-182.

Ragasa, C. Forthcoming. "Enhancing Female Participation in Agricultural Research: Rationale and Evidence." Ch. 16 in Gender in Agriculture and Food Security: Closing the Knowledge Gap, edited by A. Quisumbing, R. Meinzen-Dick, T. Raney, A. Croppenstedt, J. A. Behrman, and A. Peterman. Springer and FAO.

Schultz, T. P. 1990. "Testing the Neoclassical Model of Family Labor Supply and Fertility." Journal of Human Resources 25 (4): 599-634.

Sen, A. 1990. "Gender and Cooperative Conflicts." In Persistent Inequalities: Women and World Development, edited by I. Tinker, 123-149. New York: Oxford University Press.

Udry, C. 1996. "Gender, Agricultural Production, and the Theory of the Household." Journal of Political Economy 104 (5): 1010-1046. 



\section{RECENT IFPRI DISCUSSION PAPERS}

\section{For earlier discussion papers, please go to www.ifpri.org/pubs/pubs.htm\#dp. All discussion papers can be downloaded free of charge.}

1260. Spillover effects of targeted subsidies: An assessment of fertilizer and improved seed use in Nigeria. Lenis Saweda Liverpool-Tasie and Sheu Salau, 2013

1259. The impact of irrigation on nutrition, health, and gender: A review paper with insights for Africa south of the Sahara. Laia Domenech and Claudia Ringler, 2013.

1258. Assessing the effectiveness of multistakeholder platforms: Agricultural and rural management councils in the Democratic Republic of the Congo. Thaddée Badibanga, Catherine Ragasa, and John Ulimwengu, 2013.

1257. The impact of Oportunidades on human capital and income distribution: A top-down/bottom-up approach. Dario Debowicz and Jennifer Golan, 2013.

1256. Filling the learning gap in program implementation using participatory monitoring and evaluation: Lessons from farmer field schools in Zanzibar. Elias Zerfu and Sindu W. Kebede, 2013.

1255. Agricultural mechanization in Ghana: Is specialization in agricultural mechanization a viable business model?: Nazaire Houssou, Xinshen Diao, Frances Cossar, Shashidhara Kolavalli, Kipo Jimah, and Patrick Aboagye, 2013.

1254. A partial equilibrium model of the Malawi maize commodity market. Mariam A. T. J. Mapila, Johann F. Kirsten, Ferdinand Meyer, and Henry Kankwamba, 2013.

1253. Exchange rate policy and devaluation in Malawi. Karl Pauw, Paul Dorosh, and John Mazunda, 2013.

1252. A regional computable general equilibrium model for Honduras: Modeling exogenous shocks and policy alternatives. Samuel Morley and Valeria Piñeiro, 2013.

1251. Agricultural trade: What matters in the Doha Round? David Laborde and Will Martin, 2013.

1250. Opportunities and challenges for community involvement in public service provision in rural Guatemala. Johanna Speer and William F. Vásquez, 2013.

1249. Rising wages in Bangladesh. Xiaobo Zhang, Shahidur Rashid, Kaikaus Ahmad, Valerie Mueller, Hak Lim Lee, Solomon Lemma, Saika Belal, and Akhter Ahmed, 2013.

1248. How are farmers adapting to climate change in Vietnam?: Endogeneity and sample selection in a rice yield model. Bingxin Yu, Tingju Zhu, Clemens Breisinger, and Nguyen Manh Hai, 2013.

1247. Evaluating the local economywide impacts of irrigation projects: Feed the Future in Tanzania. Mateusz Filipski, Dale Manning, J. Edward Taylor, Xinshen Diao, and Angga Pradesha, 2013.

1246. Factor endowments, wage growth, and changing food self-sufficiency: Evidence from country-level panel data . Keijiro Otsuka, Yanyan Liu, and Futoshi Yamauchi, 2013.

1245. Impact of food price changes on household welfare in Ghana. Nicholas Minot and Reno Dewina, 2013.

1244. Parametric decomposition of the Malmquist Index in an output-oriented distance function: Productivity in Chinese agriculture. Bingxin Yu, Xiyuan Liao, and Hongfang Shen, 2013.

1243. Extreme weather and civil war in Somalia: Does drought fuel conflict through livestock price shocks? Jean-Francois Maystadt, Olivier Ecker, and Athur Mabiso, 2013.

1242. Evidence on key policies for African agricultural growth. Xinshen Diao, Adam Kennedy, Ousmane Badiane, Frances Cossar,Paul Dorosh, Olivier Ecker, Hosaena Ghebru Hagos, Derek Headey, Athur Mabiso, Tsitsi Makombe, Mehrab Malek, and Emily Schmid, 2013.

1241. A global assessment of the economic effects of export taxes. David Laborde, Carmen Estrades, and Antoine Bouët, 2013.

1240. The Women's Empowerment in Agriculture Index. Sabina Alkire, Ruth Meinzen-Dick, Amber Peterman, Agnes R. Quisumbing, Greg Seymour, and Ana Vaz, 2012.

1239. Food price volatility in Africa: Has it really increased? Nicholas Minot, 2012.

1238. The comprehensive Africa agriculture program as a collective institution. Shashidhara Kolavalli, Regina Birner, and Kathleen Flaherty, 2012. 


\section{INTERNATIONAL FOOD POLICY}

RESEARCH INSTITUTE

www.ifpri.org

IFPRI HEADQUARTERS

2033 K Street, NW

Washington, DC 20006-1002 USA

Tel.: +1-202-862-5600

Fax: +1-202-467-4439

Email: ifpri@cgiar.org 